\title{
Patch testing - Revisited
}

\section{Waseem Ahmad, Insha Latif, Gousia Sheikh, Iffat Hassan, Farhan Rasool, Abid Keen}

\author{
Post Graduate, Department of Dermatology, STD and Leprosy, GMC, Srinagar, India
}

Corresponding author: Dr. Gousia Sheikh, E-mail: drgousiasheikh@gmail.com

\begin{abstract}
Patch test is used worldwide for diagnosis of contact dermatitis. Patch test was introduced in late nineteenth century and since then has improved considerably. The methodology is simple but it requires adequate training for the results to be correctly interpreted and used. Despite having been used for over a century, it needs improvement from time to time.
\end{abstract}

Key words: Patch test, allergens, allergic contact dermatitis

\section{INTRODUCTION}

Patch testing is a well-established method of diagnosing contact allergy wherein patients with a history and clinical picture of contact dermatitis are re-exposed to the suspected allergens under controlled conditions to verify the diagnosis [1]. The results of first innovative patch-testing technique were presented by the German dermatologist, Josef Jadassohn (1863-1936) in 1895. The safety and efficacy of this diagnostic tool have stood the test of time, and is still the gold standard for the diagnosis of allergic contact dermatitis (ACD). Since its discovery, much effort has gone into understanding the chemical and toxicological aspects of test allergens, in standardization and optimization of allergens, vehicles, and concentrations of patch-test materials, in procedures of its application, as well as in reading and scoring of test reactions-all contributing to the development of an accurate, reliable, and safe test with a high reproducibility of its results. There have also been advances in the field in many areas including our basic understanding of type IV hypersensitivity reactions, emerging contact allergens, irritant contact dermatitis (ICD), systemic contact dermatitis (SCD), patch testing in children, occupational dermatitis, and reactions to biomedical devices. Improved diagnosis and management of contact dermatitis and availability of more comprehensive databases of causative contact allergens enable physicians to manage allergic contact dermatitis (ACD) by advising the patients to avoid the allergens he/she is sensitized to and providing a list of safe products that do not contain these allergens. This contribution is a review of recent literature pertaining to improving patch testing technology.

\section{INDICATIONS FOR PATCH TESTING}

Indications for patch testing may include:

- Persistent eczematous eruptions when contact allergy is suspected

- Any chronic dermatitis, especially when involving the hands, feet, face, or eyelids

- Eczematous dermatitis in individuals involved in high-risk occupations for contact dermatitis (e.g., healthcare workers, dental assistants, cosmetologists, machinists, or rubber and plastic workers)

- Dermatitis of unknown etiology

- Worsening of a previously stable dermatitis.

Patch testing also may be indicated when ACD is suspected as a complication of:

- Atopic dermatitis

- Stasis dermatitis

- Seborrheic dermatitis

- Nummular eczema

- Asteatotic eczema

- Psoriasis. 


\section{SELECTION OF ALLERGENS}

Various studies have identified more than 4350 chemicals as contact allergens with varying potential to cause ACD. However, a high proportion of ACD is caused by a relatively small number of allergens commonly found in the environment.

\section{STANDARD SERIES OF ALLERGENS}

Standard or screening series of contact allergens, which are designed to include the most common sensitizers responsible for ACD in a given region, are recommended as the initial battery for patients undergoing patch testing. The standard series are revised on a regular basis, as new allergens are identified as a cause of ACD.

There are several standard series throughout the world including the European standard series of approximately 35 allergens (determined by consensus of the European Society of Contact Dermatitis and the European Environmental and Contact Dermatitis Research Group).

Supplemental series of patch tests suitable for specific exposures, including workplace exposures, are also available to complement the standard series (eg, hairdressers, dental, or cosmetic series). The patient's clinical presentation and history help to determine whether testing with supplemental series and/or products provided by the patient is necessary [2]

\section{PROCEDURE OF PATCH TEST}

Patch testing is usually performed on the back. The outer aspect of the upper arms is an alternative. Potent topical corticosteroids applied to the test site or oral corticosteroids ideally should be discontinued at least two weeks before patch testing $[3,4]$. Oral antihistamines may be continued during patch testing, as they have minimal if any effect on the mechanisms of delayed hypersensitivity. Patients should avoid irradiation from both artificial and natural (sunlight) sources of ultraviolet (UV) radiation before patch testing as it can reduce the number of antigenpresenting cells in the skin and the intensity of patch test reactions.

The most commonly accepted technique for patch testing involves the application of test allergens under occlusion onto the skin of the upper back for two days. Allergens are applied in standard amounts to aluminum or synthetic material chambers mounted on non-occlusive tape strips. The patches typically are left in place for a period of two days (48 hours), which allows adequate penetration of the allergen into the skin. To reduce the number of false positive readings, the initial evaluation is generally performed between 15 and 60 minutes after the patches are removed, when the transient erythema has resolved.

A second reading is critically important to distinguish irritant reactions (which fade) from true allergic reactions (which persist) and to identify allergic reactions that do not appear at the time of patch removal [5]. The time of the second reading varies among different patch testing centers but generally is on day four or five.

Correct reading and interpretation of patch test reactions require the skills of a trained clinician and is done according to the scoring system developed by The International Contact Dermatitis Research and has been accepted by the North American Contact Dermatitis Group [6].

To further refine patch testing, the following aspects might be addressed.

\section{STABILITY OF ALLERGENS}

Knowledge about allergen stability available is minimum. This may result in applying commercial allergens without knowing how long they are biologically active. This information deserves to be open source, either on the allergen package insert or on the Internet. Bruze and colleagues determined an inadequate stability of isocyanates, which are widely used in industry and are causative agents of ACD and asthma. This may result in misdiagnosis of ACD from isocyanates on the basis of unstable allergens.

\section{TRUE ALLERGEN IDENTIFICATION}

We often assume that we know what chemical is causing a positive patch-test reaction. When patchtesting with para-phenylenediamine (PPD) yields a positive result, one is not sure whether the patient is allergic to PPD or to the metabolic or degradation product on the skin after contact with PPD [7]. 
Even when an allergen is identified (as in the case of PPD in hair dye), it's processing in the body and the critical immunogenic steps involved are not known [8]. furthermore, in the case of hair dye, allergens other than PPD may be overlooked. Knowledge about a structure of allergen, processing, and recognition by the body may allow structural modifications of common allergens to allow their use without inducing allergic reactions.

Since numerous allergens are present in natural products, chemical identification of the antigen causing ACD becomes difficult.

A clearer view of the chemical mechanisms of allergens and better definition of chemical structure is needed to know whether the true culprit is the allergen itself, a cross-contaminant, or a skin metabolite [8].

\section{NEW T.R.U.E-TYPE TESTS}

The Thin-Layer Rapid Use Epicutaneous (T.R.U.E.) Test (Allerderm, Petaluma, CA) is commonly used by the American dermatologists for its simplicity of application [9]. A more efficient, economical and convenient patch test (with predosed standardized allergens)which is commercially available and can be easily applied to the patient without technical assistance is needed.

\section{SERIAL DILUTIONS OF ALLERGENS}

Most patients are tested with one patch-test concentration. Fragrance mix I may because irritation and may result in dermatitis without an actual allergy present. On the other hand, nickel is tested at 2,500 to 5,000 parts per million (ppm) whereas some individuals may react to as little as 1 ppm. So testing with serial dilutions helps to identify individuals who can develop dermatitis even after exposure to a minimal concentration of allergen. Not everyone reacts to the same concentration of a substance; some may react only to higher concentrations, while some may react to very low concentrations.

\section{IRRITANT POTENTIAL OF ALLERGENS}

Many allergens are irritants as well, resulting in false positive patch tests due to lack of true allergic response. Examples include formaldehyde, wool wax alcohol (lanolin), paraben mix, and carbamate. Occlusion also enhances the irritancy potential of some allergens.
Future patch-test design should be able to identify methods of demonstrating true allergic reactions without false positives, which can be achieved by advances in dermato- pharmacokinetics.

\section{PATCH-TEST READING}

The international standard for reading patch test results is 48 hours although it may be accurately performed and read within 24-hour [10]. A shorter applicable time will be more convenient, hence needs to be discussed. Various studies in animals and humans have shown that chemicals may need only 30 minutes of application for percutaneous penetration [11].

\section{PATCH-TEST BANKS}

National, regional, and international patch-test banks could distribute uncommon allergens to dermatologists for a flat annual fee and could also record response data to determine the frequency of sensitivity to rare or new allergens (thus serving as an early warning system) [12].

\section{FALSE-NEGATIVE RESULTS}

Some patients are intolerant to a substance in a manner suggestive of ACD but patch test is negative which can be explained by compound allergy. The false-negative result could also be due to low concentration or to an inappropriate vehicle [13]. A systematic investigation needs to carry out to determine the maximal nonirritant concentration of allergen to avoid false negativity.

\section{SPECIAL SERIES}

Besides the standard series of allergen available, an evidence-based approach needs to be followed to add new and rare antigens to formulate special series. Thus, positive results may not correlate with clinical relevance [14].

\section{INTRADERMAL TESTING}

Intradermal injection of an allergen is an old technique that is rarely used today [15]. There are cases in which patch testing yields negative results but intradermal injection yields positive reactions. Thus the use of this technique needs reconsideration in a systematic manner. 
www.odermatol.com

\section{CONTACT ALLERGY VERSUS EXTRACUTANEOUS CLINICAL DISEASE}

We need to expand our knowledge of extracutaneous cell-mediated immunity as some reactions may not be expressed in the skin but may cause other immunological reactions $[16,17]$.

\section{CLINICAL RELEVANCE OF POSITIVE PATCH-TEST REACTIONS}

Patch-test results may signify an immunologic response, but this may have little or no clinical significance $[18,19]$. Enhanced quantitative understanding of clinical relevance would allow determining the probability of a true clinical allergy, given a positive patch test result.

\section{SKIN BIOENGINEERING}

Many instruments used to measure skin functions eg, transepidermal water loss, conductance, and capacitance will help us in making a more definitive approach to ACD and help in differentiating it from irritant dermatitis. These bioengineering instruments will provide efficient measurements and qualitative assessments of patch-test results.

\section{IN VITRO DIAGNOSTIC METHODS}

An in vitro test for cell-mediated immunity is possible and could be accomplished experimentally, perhaps by peptide reactivity measurements [20]. This will enable patients to give a small amount of blood for an accurate diagnosis.

\section{USING RIBONUCLEIC ACID FOR DIAGNOSIS OF ACD}

Ribonucleic acid (RNA) obtained from tape stripping or skin washes could be used to diagnose ACD. In molecular biology, RNA assays from skin cells can be performed quickly with kits. This could result in a diagnosis of ID and ACD on the basis of RNA [21].

Once the genetic code of a patient with ID or ACD is determined, therapy can be optimized with pharmaco- epigenetics (a new field in pharmacology), which can help in finding inter-individual differences in drug response [22].

\section{WORLD WIDE WEB}

The World Wide Web can help in increasing ACD knowledge refinement and management. It should focus on international allergen alternatives for health care workers and patients. It can help in bringing together contact dermatitis groups for collaboration in ACD management. Furthermore, groups should continue to work together to correct discrepancies.

To conclude, the points highlighted in this article will help in improvising over the conventional patch testing which in turn will be more beneficial to the patients.

\section{REFERENCES}

1. Por A, Ket NS. Investigative techniques in contact dermatitis. In: Ket NS, Goh CL, editors. The Principles and Practice of Contact and Occupational Dermatology in the Asia-Pacific Region. World Scientific: New Jersey; 2001. p. 47-57.

2. Dooms-Goossens A. Patch testing without a kit. In: Practical contact dermatitis: A handbook for the practitioner, Guin JD (Ed), McGraw-Hill Inc., New York 1995. p.63.

3. Sukanto H, Nater JP, Bleumink E. Influence of topically applied corticosteroids on patch test reactions. Contact Dermatitis. 1981;7:180

4. Anveden I, Lindberg M, Andersen KE, Bruze M, Isaksson M, Liden C, et al. Oral prednisone suppresses allergic but not irritant patch test reactions in individuals hypersensitive to nickel. Contact Dermatitis. 2004;50:298-303.

5. Uter WJ, Geier J, Schnuch A. Good clinical practice in patch testing: readings beyond day 2 are necessary: a confirmatory analysis. Members of the Information Network of Departments of Dermatology. Am J Contact Dermatitis. 1996;7:231-7.

6. Wilkinson DS, Fregert S, Magnusson B, Bandmann HJ, Calnan CD, Cronin E, et al. Terminology of contact dermatitis. Acta DermVenereol. 1970;50:287-92.

7. Aeby P, Sieber T, Beck H, Gerberick GF, Goebel C. Skin sensitization to $\mathrm{p}$-phenylenediamine: the diverging roles of oxidation and $\mathrm{N}$-acetylation for dendritic cell activation and the immune response. J Invest Dermatol. 2009;129:99-109.

8. Krasteva M, Bons B, Ryan C, Gerberick GF. Consumer allergy to oxidative hair coloring products: epidemiologic data in the literature. Dermatitis. 2009;20:123-41.

9. Fischer T, Kreilgard B, Maibach HI. The true value of the TRUE Test for allergic contact dermatitis. Curr Allergy Asthma Rep. 2001;1:316-22.

10. Ale SI, Maibach HI. 24-hour versus 48-Hour occlusion in Patch Testing. Exog Dermatol. 2003;2:270-6.

11. Rougier A, Lotte C, Maibach HI. In vivo percutaneous penetration of some organic compounds related to anatomic site in humans: predictive assessment by the stripping method. J Pharm Sci. 1987;76:451-4

12. Andersen KE, Rastogi SC, Carlsen L. The Allergen Bank: a source of extra contact allergens for the dermatologist in practice. Acta Derm Venereol. 1996;76:136-40.

13. de Groot AC, Bruynzeel DP, Jagtman BA, Weyland JW. Contact allergy to diazolidinyl urea (Germall II). Contact Dermatitis. 1988; 18:202-5.

14. Cheng LS, Alikhan A, Maibach HI. Creating an electronic collaboration between international contact dermatitis groups. 


\section{www.odermatol.com}

Contact Dermatitis. 2009;61:59-60.

15. Herbst RA, Lauerma AI, Maibach HI. Intradermal testing in the diagnosis of allergic contact dermatitis. A reappraisal. Contact Dermatitis. 1993;29:1-5.

16. Svedman C, Ekqvist S, Moller H,Björk J, Pripp CM, Gruvberger B, et al. A correlation found between contact allergy to stent material and restenosis of the coronary arteries. Contact Dermatitis. 2009;60:158-64.

17. Ekqvist S, Lundh T, Svedman C, Björk J, Möller H, Nilsson LA, Bruze M. Does gold concentration in the blood influence the result of patch testing to gold? Br J Dermatol. 2009;160:1016-21.

18. Lachapelle JM. A proposed relevance scoring system for positive allergic patch test reactions: practical implications and limitations. Contact Dermatitis. 1997;36:39-43.

19. Marrakchi S, Maibach HI. What is occupational contact dermatitis? An operational definition. Dermatol Clin. 1994;12:477-84.

20. Gerberick GF, Vassallo JD, Foertsch LM, Price BB,
Chaney JG, Lepoittevin JP. Quantification of chemical peptide reactivity for screening contact allergens: a classification tree model approach. Toxicol Sci. 2007;97:417-27.

21. Morhenn VB, Chang EY, Rheins LA. A noninvasive method for quantifying and distinguishing inflammatory skin reactions. J Am Acad Dermatol. 1999;41:687-92.

22. Gomez A, Ingelman-Sundberg M. Pharmacoepigenetics: its role in interindividual differences in drug response. Clin Pharmacol Ther. 2009;85:426-30.

Copyright by Waseem Ahmad, et al. This is an open-access article distributed under the terms of the Creative Commons Attribution License, which permits unrestricted use, distribution, and reproduction in any medium, provided the original author and source are credited.

Source of Support: Nil, Conflict of Interest: None declared. 